Karen M. Lauridsen*

\title{
Language Policy: How do organisations ensure that instructive texts are written in a language that is understood by their end users?
}

\begin{abstract}
Like any other text, instructive texts function within a given cultural and situational setting and may only be available in one language. However, the end users may not be familiar with that language and therefore unable to read and understand the instructions. This article therefore argues that instructive texts should always be available in a language that is understood by the end users, and that a corporate communication policy which includes a language policy should ensure that this is in fact the case for all instructive texts.
\end{abstract}

\section{Introduction}

Instructive texts, like any other kind of text, function within a cultural and situational setting. Today it cannot be taken for granted that such a setting is monolingual, and the production and successful reception of instructive texts therefore depend on the availability of instructions in a language that can be understood by the end user. As a consequence of this, it would seem obvious that the choice of language for a given instructive text is informed by an overall language policy, taking into consideration the obvious target groups for these instructions.

Consider the following scenario: An immigrant or a tourist at the pharmacy does not understand the instructions regarding his wife's medication as they are only available in the local language. How many tablets, how many times a day for how many days? How soon can he expect her to get better? And if she does not, how long should he wait

\footnotetext{
* Karen M. Lauridsen

Aarhus School of Business, University of Aarhus

Knowledge Communication Research Group

Fuglesangs Allé 4

DK-8210 Aarhus V

kml@asb.dk
}

Hermes - Journal of Language and Communication Studies no 40-2008 
before he contacts the doctor again? He clearly does not understand most of what the pharmacist tries to explain to him, and it will not help him that there is a patient package insert (PPI) in the language of his host country. Finally he gives up, pays for the medication and leaves the pharmacy very frustrated. A very unfortunate, but not a very unusual situation.

In most countries, PPIs are in one language only and thus not necessarily understood by the end users (the patient and/or her family) if they do not master the local language. This pertains to prescription as well as non-prescription medication, whereas other products such as e.g. electronic equipment, ordinary household machines or cosmetics, more often than not seem to come with instructive texts in several (major) languages. 'How to apply your mascara?' is not a question of life and death, but that might be the case for a substantial amount of medication on the market if it is not taken as prescribed.

Against the backdrop of these general observations, it is interesting to see whether, for any type of product, there is an instruction available to the end user in a language that $\mathrm{s} / \mathrm{he}$ can read and understand. This question may be approached in different ways. One would be to sample instructive texts for a range of different product categories to see whether these texts are available to the customers or end users in one or several relevant languages, or to survey the official language policies of production companies within different industries. While this would exemplify explicit or implicit corporate language policies and their implementation, the outcome would undoubtedly reveal that some companies or industries have language policies and make informed choices as to the language(s) of their instructive texts. Others do not.

The approach adopted here is rather to see how and to which extent the language of instructive texts is an issue that is dealt with in the existing literature on language policy, taking it for granted that the awareness of this issue would be reflected in the way it is, or is not, covered in that literature. We will therefore not concern ourselves with the instructive texts as examples of a specific genre, with the discourse of instructive texts, or with a semiotic analysis of instructive texts, etc. Instead, we will take as our point of departure that instructive texts are examples of knowledge communication, more specifically, the dissemination of specialised knowledge, and that this knowledge should be communica- 
ted in a language that is understood by the persons who need the information imparted by means of these instructions.

Following an introduction to language policy in general, this paper focuses on the literature on corporate language policy and corporate strategy to see to which extent language policy literature includes considerations as regards the language needs of the end user of any product or service, and to which extent language policy is considered a strategic issue in the literature on corporate strategy. On the basis of the answers to these two questions, recommendations will be made concerning future research on this subject as well as future policy development and implementation.

Issues regarding the quality of the text and its translation, an adequate level of discourse, or the intended target groups and their backgrounds for understanding the message of the text, are sometimes also included under the umbrella term of language policy. ${ }^{1}$ These issues will not be considered below, however; the same goes for language policy in the sense of correct spelling, punctuation, etc. ${ }^{2}$ These are important aspects that should not be disregarded at any level in companies and organisations, but they fall outside the scope of this paper.

\section{Language policy}

The concept of language policy is multi-faceted and includes education and training as well as the skills and competences needed in a professional - or non-professional - context when people interact in speech or writing across linguistic and cultural borders. Furthermore, the concept covers the choice of language or languages used for human interaction in particular settings. Finally, language policy matters may be considered at different levels, first of all at the level of international organisations or supra-national bodies like the UN or the EU, cf. section 2.1; at national level, cf. section 2.2.; or at the level of individual organisations or companies, cf. section 3 below. These three levels will be dealt with in turn, the main focus being on corporate language policies and on how

1 Such issues are typically covered in translation studies or discourse analysis.

2 The choice of standard, e.g. British or American English, or issues concerning punctuation, spelling, etc. are typically found in company-internal documents prepared by the organisation's communications department. 
104

to determine which languages should be used in internal as well as external corporate communication.

\subsection{Language policy at supra-national level}

International organisations need to establish a language policy in order to facilitate communication between their member states. The UN has a language regime of six major world languages, ${ }^{3}$ whereas in the European Union, the national languages of the member states are the official EU languages. As a result, these national languages have a privileged status in the EU context to the detriment of the large number of indigenous, immigrant and other minority languages, which might in fact be spoken by a much larger group of people than the national languages of the small member states. In this context, Danish is an example of a small language which is a national language and, therefore, an official EU language even though it is only spoken by little more than 5 million people world-wide, whereas for instance Catalan is a minority, non-official language spoken by more than 7.5 million people. In countries with large minority language populations, including immigrants of nonEuropean origin, a large share of the inhabitants do not necessarily understand instructions in the official language of the country.

This leads to the political question of linguistic human rights that are being widely discussed, cf. e.g. Grin (2005) and Paulston (1997). While the linguistic human rights perspective is relevant for the protection and promotion of minority languages and linguistic diversity, its major weakness is that it almost exclusively relies on moral considerations. Grin (2005) therefore argues that in order to underpin the moral considerations of public opinion and politicians, it is necessary to draw on the tools of policy evaluation. These tools should in fact be applied in the assessment of the national language policies of most countries today.

\subsection{Language policy at national level}

A national language policy is typically formulated in order to establish the language needs of a specific country. It identifies the first and second languages of the country as well as the foreign languages in which proficiency is needed, and which therefore are included, or should be in-

3 Arabic, Chinese, English, French, Russian, and Spanish 
cluded, in the foreign language curricula of the education system. Furthermore, the language policy states the appropriate proficiency levels to be achieved by foreign language learners (Lo Bianco 1987 in Tisdell 1998:135).

According to Tisdell (ibid.), there are basically two reasons why governments need to formulate a national language policy:

\begin{abstract}
A country whose majority language constitutes a minority language outside this country, needs to formulate a language policy which protects this national language against the influences of larger, more prominent language groups in neighbouring countries. [In countries with large groups of immigrants and a continuous shift in population due to ongoing immigration] language policies need to establish procedures to ensure that immigrants acquire the language of the majority. Also, the language policies of these countries need to define the status and the maintenance procedures of the languages of immigrant groups.
\end{abstract}

Denmark is an example of "a country whose majority language constitutes a minority language outside the country itself". The Danish national language policy discussion is therefore concerned with how Danish can be maintained as a full language at a time when English is taking over in many domains, notably in research, higher education, international trade, transport, etc. ${ }^{4}$ as well as other growing sectors such as the tourist and entertainment industries. At the same time there are also large groups of immigrants for whom Danish is not the first language, and for whom adequate language provision must be in place so that these people have the opportunity, or obligation, to learn Danish if they are to stay in the country for any length of time.

It is equally important, however, that the inhabitants of the country, and in particular people employed in its business and industry sectors, are prepared to meet the linguistic challenges of globalisation, and that these people have the necessary and sufficient foreign language and intercultural skills and competences to do so. As a consequence there seems to be at least one more important reason why a country should develop an explicit national language policy, viz. to ensure that sufficient foreign language education and training be provided in the education system so that all inhabitants have the opportunity to acquire the

4 Kulturministeriet (2003). 
106

necessary foreign language skills and competences. In the knowledge society, everyone needs to be able to understand impressive amounts of knowledge communication in his/her professional and private lives. This obviously also applies to instructive texts, not least when we turn to the corporate level.

\section{Corporate Language Policy}

Corporate language policy is as yet not a fully established field of research, however, and the literature on this topic is spread across a number of quite diverse subject areas. Most of the literature, however, concerns communication in large multi-national companies. For instance, Dhir \& Gòkè-Paríolá (2002:241) argue that

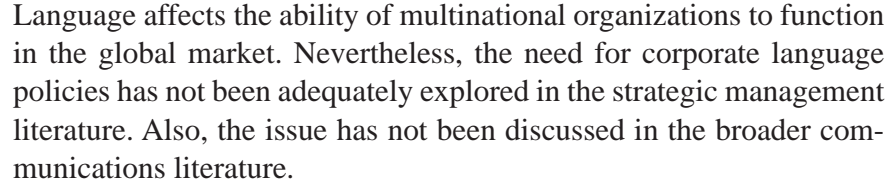

Language affects the ability of multinational organizations to function in the global market. Nevertheless, the need for corporate language policies has not been adequately explored in the strategic management literature. Also, the issue has not been discussed in the broader communications literature.

While it would be difficult to disagree with this statement, it is still worth noting that Dhir \& Gòkè-Paríolá discuss the development of a corporate language policy by drawing upon insights from traditional language planning and the socio-political context of community and nation building, cp. 2.1 above. Their conclusion is that "just as postcolonial states had to adopt a more pluralistic linguistic ideology, so will multinational corporations in the emergent knowledge-based global economy” (2002:250). Thus, they argue against a standardisation approach like, for instance, English as the corporate language, and instead they advocate a diversity approach to the languages used within the company.

Moreover, Dhir \& Gòkè-Paríolá point at two research areas, the literature of which is relevant for the discussion of a corporate language policy, i.e. strategic management literature and (corporate) communication literature. These will be dealt with in 3.1 and 3.2 below.

Probably because the term covers such diversity, there does not seem to be a generally adopted definition of language policy. In what follows, organisational or corporate language(s) will be understood within the framework of the following questions that should be addressed in the language policy: 
- Which language or languages are to be used in which settings within the organisation?

- Are the necessary and sufficient linguistic and inter-cultural resources available in the organisation at any given time?

- Are the necessary and sufficient linguistic and intercultural resources made available as part of the recruitment and executive education policies of the organisation? Or are the linguistic needs met e.g. by outsourcing translation or interpretation tasks to organisation-external experts?

- Is the language policy integrated into the communication policy as a result of strategic decisions, and does the overall communication policy cover all internal and external communication of the organisation?

\subsection{Strategic management literature}

A survey of the massive amount of corporate strategy literature would be a daunting task, and certainly outside the scope of an exploratory paper like this one. A random selection of such literature yields conspicuously meagre results, however. For instance, a widely used and very comprehensive textbook of more than 800 pages on corpora strategy (Lynch 2006) does not include any references at all to language or linguistic policy. Its reference to communication is limited to a few pages concerned with strategy implication, that is, a section on "Communicating with customers and stakeholders" (2006:172ff). In this context, Lynch lists three key strategic principles (2006:174):

- Organisations communicate with their customers in order to inform and persuade them about the merits of their products and services. This will assist in establishing the sustainable competitive advantages of the product.

- Cost-effectiveness is the main criterion when assessing communication proposals. Costs are usually relatively easy to estimate, but the effects of some promotional areas may be more difficult to assess.

- Different types of customers will need different forms of communication. Each will operate to communicate and secure the competitive advantages of the organisation. 
108

Even though the instructive texts that we are considering could be said to be part of the communication to inform customers about the merits of the products mentioned under the first bullet point, what Lynch is thinking of is primarily what we would consider marketing communication and sales promotion. The message of the third bullet point is couched in such general terms that the linguistic needs of the end users of a given product cannot be said to be included under that point. In a later section he briefly mentions the communication of a strategic plan to the employees of a given organisation (2006:627f), but nothing about the language or languages of this plan. Despite the fact that there are a couple of sections on corporate communication to internal or external stakeholders, the language issue is not at all covered in the book. Steger actually includes a chapter on Corporate Communication (2003:205222). However, this chapter is limited to what we would call PR communication in the widest sense and, again, language policy matters are not considered at all.

It is obviously impossible to analyse what is not there, but these references serve the purpose of showing that strategic management literature in general only comprises corporate communication to a very limited extent, and that the issue of language policy is not included.

\subsection{Language policy at corporate level}

Most of the literature on corporate communication that includes the question of languages seems to focus on international human resource management and communication in multinational companies, cf. e.g. Dhir (2004;2005), Dhir \& Gòkè-Paríolá (2002), Feely \& Harzing (2003), Marschan-Piekkari et al. (1999a) and Marschan-Piekkari et al. (1999b) as well as Vaara et al. (2005), who discuss the internal power implications of a corporate language policy in which one language is given priority by being defined as the one and only corporate language. Language skills and competences are thus seen as a factor that may change existing power structures and thereby constitute a valuable asset for the individual who possesses these skills and competences to the detriment of those who do not.

The evolution of the knowledge economy, globalisation and an increasing diversity of the workforce are general trends in society. Closely connected with these trends is obviously the question as to which 
language or languages should be used for communication. There are basically two approaches, viz. to see language diversity as creating communication barriers, or to see language diversity as an asset.

Feely \& Harzing (2003) focus on the language barriers and advocate a language audit for the individual organisation, cf. Reeves \& Wright (1996), in order to determine the organisation's foreign language requirements and benchmark these against their capabilities. They identify possible impacts of language barriers in relation to buyer/ seller relationships, foreign market expansion, joint venture, HQ-subsidiary relationship, and staffing policies, and they list a set of options for managing the language problems. Again, communication within the multinational company or in business-to-business relations is the case in point.

Dhir $(2004 ; 2005)$ is also concerned with multinationals and suggest that just as these companies would have a portfolio of currencies or financial assets, their workforce would also represent a portfolio of languages that should be considered an asset for the organisation. He thus sees both a currency and a language as being a unit of exchange, a unit of account, and a store of value. As a unit of exchange, a language is used in exchange of information and knowledge; as a unit of account, it is used in accounting through narratives; and as a store of value, it is used for storing the value of knowledge and know-how (2005:364). By applying social judgment theory, he develops a judgment-analytic framework within which the individual organisation may assess its value of languages.

On the basis of the above it may now be concluded that language policy literature is concerned with supra-national, national and organisational policies, none of which addresses the needs of the customer, client, consumer, or end users of instructive texts in a language they are able to read and understand. The corporate communication literature that does discuss the customers and clients, etc. as target audiences, does not seem to pay attention to which languages the organisation should use when addressing this very important stakeholder group. The organisation-internal perspectives of corporate language policy, including the positive view of linguistic diversity in a non-standardised environment, may have positive implications within the framework of the operational recommendations that will be presented in the discussion 
110

below; these implications, however, do not seem to be addressed in the current literature.

\section{Corporate communication in practice}

So far the two questions asked at the beginning of this paper have been answered in the negative. Language policy is not considered a strategic issue in the literature on corporate strategy, and the literature on corporate language policy does not include considerations as regards the needs of the end user as far as language choice is concerned. In other words, we have not encountered literature on policies that also positively address the issue of language(s) in instructive texts.

However, there is no doubt that, definitely at the operational level and possibly even at the strategic level, there are (explicit or implicit) policies in place in companies and organisations as to which languages function as the means of communication between the companies and their customers, clients or consumers (end users). This applies to their corporate communication, their marketing communication, including advertisements and commercials, and their public relations communication, etc. both in printed and electronic forms.

One example of this would be corporate websites. There are basically three scenarios:

1. Website in national language only (e.g. Danish).

2. Website in national language and/or one/two major foreign language, English is typically one of them.

3. Website in several languages.

The standardised approach of using one language only is seen in the first example. A Danish website like e.g. www.apoteket.dk ("the pharmacy") only caters for customers and end users who are able to read and understand Danish. Customers who cannot do that, will have to consult similar websites in a language with which they are more familiar, provided that such websites exist. As Danish is a small language which might be understood by most people in other Nordic countries, but only by a very limited number of other people who have not grown up with Danish as their first language, the pharmacy website is of no help at all to the immigrant family, or to an American tourist, a Chinese student, 
an Indian software engineer or someone else working in the country for a short period of time.

If the standardised approach is adopted with English as the lingua franca like in www.lego.com, it goes without saying that the target audience that is able to read and understand the information increases considerably. As a matter of fact, major Danish companies often have UK and US websites as well as a German site. ${ }^{5}$

Other major Danish companies like Novo Nordisk (www.novonordisk.com) and Grundfos (www.grundfos.com) have a corporate website in English (the .com website) with links to a range of countries and languages relevant for their subsidiaries and customers.

The same scenarios would undoubtedly apply to other genres and media, so in reality most companies and organisations would take the languages of their customers, clients and consumers into consideration and make their texts available in an appropriate language for any relevant cultural and situational context.

The question remains, then, why this is not always the case. For instance, why are there not PPIs available for the non-Danish speaker who buys medication for his wife at a Danish pharmacy? There are at least two answers to that question: (1) Danish is considered the language of the consumer (end user) in Denmark, and the instructions are available in Danish. Denmark is still considered a monolingual society; and (2) as a matter of fact, the pharmaceutical company sells, or at least markets, its products to the doctors (general practitioners) who then prescribe the medicine to the patients. The primary marketing efforts for all prescription medicine are therefore geared towards the doctors rather than the patients.

However, the PPIs are not marketing communication. They are informative and instructive texts that inform and guide the patients as the end users of the products.

It cannot be taken for granted that all patients are able to read the Danish instructions. The same might apply in connection with other cases as well, but the PPIs of pharmaceutical products are a pertinent case in point.

5 A Lego website is available for the following three regions: UK, US and Germany (www.lego.de). 
What should be done about this problem? If the company does not want to insert a whole booklet with the information and instructions in several languages, one possibility would be that the content of the PPIs was available in other languages on a website and could be printed on demand at the pharmacy.

\section{Discussion and conclusions}

Instructive texts such as inserts, PPIs, etc. ought to be available for the consumer in a language that $\mathrm{s} / \mathrm{he}$ can read. In principle, this applies to the consumers of any product that is sold with an insert containing information and instructions for the end user. This claim could be considered a subjective as well as a moral judgment rather than a conclusion drawn on sound evidence. However, if an audit is carried out to inform the development of a policy, cf. Feely \& Harzing (2003), and this policy is then evaluated after implementation, cf. Grin (2005), the claim would be made on a much sounder basis. Such a process is therefore recommendable.

A corporate language policy comprising all internal as well as external communication of a given organisation or company, would clearly state the language(s) in which the instructive texts were to be available. Such a policy, based on a language audit and subsequently evaluated, would thus exploit some of the tools that are applied in somewhat different contexts in the literature. However, the policy evaluation that Grin (2005) recommends for a national policy could equally well be applied at the corporate level.

The above recommendations would be seen by many as implying a considerable increase in the production costs and thereby make the product less competitive. While this might be true in some cases, the validity of this argument would depend on the linguistic resources available in the company. Different language tasks may require different solutions. Feely \& Harzing list possible solutions, including e.g. contracting translators and interpreters as well as recruitment and training of existing staff. As a consequence of this there might be what they term "language nodes" in a company, that is, key personnel who "[establish] themselves as the default communication channel between the company and the external world" (2003:46). While these people may not be language experts per se, they may be trained to take on the tasks 
of translating pertinent documents like e.g. instructive texts for the consumer or end user.

The argument against providing the instructive texts in various different languages, i.e. that it is difficult to find people who would be able to translate the instructive texts into languages outside the regime of major European languages, would not be valid if the organisation made use of a combination of these different solutions. If a diversity approach is taken to language policy at national and corporate level, there will be people available to translate the instructive texts to a wide range of major languages, including e.g. Arabic, Chinese, etc. The same applies to the languages of the immigrant population in a given country. Thus a national and a corporate language policy may be said to be working in tandem.

It goes without saying that all organisations will need to work out a policy that works for them, given their specific needs as well as the resources available in their specific contexts. There is therefore not a "one size fits all” way to meet this challenge.

The above recommendations would underpin Dhir's (2005) idea that language should be assessed as having a value on the market in the same way as a currency has a value on the financial markets. The more linguistic resources that are available among people in general, and specifically among company staff, the better equipped the organisation will be to meet the challenges of today's multilingual global society. The diversity of languages is thus an asset for the organisation and will allow employees to share knowledge and exchange information among themselves and with external stakeholders.

Instructive texts like e.g. the PPIs seem not be included among the categories of genres typically covered by the communication strategy (corporate communication, marketing communication, PR, etc.). Therefore the communication strategy should be revisited as should its implementation at the tactical and operational levels in order to ensure that all relevant communication is covered by the policy and its implementation.

Last, but certainly not least, the communication strategy should be clearly linked to a language policy that ensures that all communication is expressed in one or more language(s) that can be read and understood by all relevant target audiences. 
However, more research is needed in order to underpin the recommendations at the level of policy development and implementation. Empirical studies should be made of existing language policies and how they are linked to the communication policies (strategies and their implementation) in companies and organisations. If possible, examples of good practice should be identified.

On the basis of this, recommendations should be made for corporate language policies that take into consideration the language needs of all the stakeholders with whom the company communicates. These recommendations might be based on a language audit (Wright \& Reeves 1996), and they might be underpinned by objective arguments like, for instance, the ones suggested by Grin (2005) as regards policy evaluation, or the ones suggested by Dhir (2005) as regards the value of language. This would ensure that the recommendations would not be rejected for reasons of sheer (lack of) cost-effectiveness, but stand a better chance of being accepted because of the competitive advantage that they offer to the organisation or company in question.

The corporate communication literature should encompass studies on the linguistic needs of end users, and how these needs can be accommodated in the corporate communication strategies and their implementation. In our increasingly globalised environment, multilingualism and multiculturalism is the rule rather than the exception, and this has implication for the way companies communicate with their stakeholders.

Language policy as a strategic issue should be reflected, on a par with communication policies, in the literature on corporate strategy - as well as in the actual strategies, of course. However, this would be the topic of further research and policy recommendations.

\section{References}

Cavidies, Alexander 2003: The Role of Language in Nation-Building within the European Union. In Dialectical Anthropology 27, 249-268.

Dhir, Krishna S. 2004: Language as a corporate asset. In Oliver, S.M. (Ed.) Handbook of Corporate Communication and Strategic Public Relations. London: Routledge, 393-414.

Dhir, Krishna S. 2005: The value of language: concept, perspectives and policies. In Corporate Communications: An International Journal 10:4, 358-382. 
Dhir, Krishna S. \& Abíodún Gòkè-Paríolá 2002: The case for language policies in multinational corporations. In Corporate Communications: An International Journal 7:4, 241-251.

Feely, Alan J. \& Harzing, Anne-Wil 2003: Language Management in Multinational Companies. In Cross Cultural Management 10:4, 37-52.

Grin, Francois 2005: Linguistic human rights as a source of policy guidelines: A critical assessment. In Journal of Sociolinguistics 9:3, 448-460.

Kulturministeriet 2003: Sprogpolitisk redegørelse. http://www.kum.dk/sw8586.asp

Lo Bianco , J. 1987: National Policy on Languages. Canberra: Commonwealth Department of Education, Australian Government Publishing Services.

Lynch, Richard 2006: Corporate Strategy, $4^{\text {th }}$ ed. FT Prentice Hall (Pearson Education).

Marschan-Piekkari, Rebecca, Denise Welch \& Lawrence Welch 1999a: Adopting a common corporate language: IHRM implications. In The International Journal of Human Resource Management 10:3, 377-390.

Marschan-Piekkari, Rebecca, Denise Welch \& Lawrence Welch 1999b: In the shadow: the impact of language on structure, power and communication in the multinational. In International Business Review 8, 421-440.

Paulston, Christina Bratt 1997: Language Policies and Language Rights. In Annual Review of Anthropology 26, 73-85.

Reeves, N. \& Feely, A. 1996: Linguistic Auditing. Clevedon: Multilingual Matters.

Schumacher, Horst 2003: Wahl der Konzernsprache im multinationalen Unternehmen. Betrachtungen zur Entwicklung der internen (und externen) Kommunikation der grossen Gruppen. In Nielsen, Martin (Hrsg.) Wirtschaftskommunikation im Wandel. Dynamik, Entwicklung und Prozessualität. Europäische Kulturen in der Wirtschaftskommunikation. Wiesbaden: Deutscher Universitäts-Verlag, 189-195.

Steger, Ulrich 2003: Corporate Diplomacy. The Strategy for a Volatile, Fragmented Business Environment. Chichester, West Sussex: John Wiley \& Sons Ltd.

Tisdell, Mariel 1998: Socio-economic aspects of language policies: an Australian perspective. In International Journal of Social Economics 25:2/3/4.

Vaara, Eero, Janne Tienari, Rebecca Piekkari \& Risto Säntti 2005: Language and the Circuits of Power in a Merging Multinational Corporation. In Journal of Management Studies 42:3, 595-623.

Wright, S. 1995: Language planning and policy making in Europe. In Language Teaching July. Cambridge: Cambridge University Press, 148-159. 


\section{Call for papers}

\section{The 'G-word'. Critical understandings of globalisations in a corporate context}

The Hermes vol. no. 43 will be a thematic issue on globalisation. Globalisation is a very commonly used term, which nevertheless covers a wide range of meanings. The special issue wants to focus on the variety of the many notions and implications of globalisation. Particularly critical understandings, challenging the implication that there should be a consensus of what globalisation means, are welcome.

We therefore invite interested researchers to submit abstracts on innovative and original work, either empirically studying the concepts of globalisations, or their theoretical implications. The abstract should not exceed two pages, a page defined as 2200 characters without blanks. Deadline for the abstracts is the $1^{\text {st }}$ of April 2008.

Please send the abstracts as attachments to either one of the editors:

- Associate professor Martin Nielsen:mn@asb.dk

- Associate professor Iris Rittenhofer: iri@asb.dk

The editors of the special issue are members of the research group for the study of corporations and their environments in culture, CEBERU, at ASB, Aarhus University.

Among the received abstracts the editors will choose six contributions. All contributors will be informed on our decision by $15^{\text {th }}$ of April 2007. The final deadline for the article is $31^{\text {st }}$ of January 2009. The volume will be published in September 2009. 